\title{
Islamic Wet Cupping and Risk Factors of Cardiovascular Diseases: Effects on Blood Pressure, Metabolic Profile and Serum Electrolytes in Healthy Young Adult Men
}

\author{
Bassem Refaat $^{1 *}$, Adel Galal El-Shemi ${ }^{1,2}$, Anwar Abdelgayed Ebid ${ }^{3}$, Ahmed Ashshi ${ }^{1}$ and Mohammad A BaSalamah ${ }^{4}$ \\ ${ }^{1}$ Laboratory Medicine Department, Faculty of Applied Medical Sciences, Umm Al-Qura University, Al Abdeyah, Makkah, PO Box 7607, KSA \\ ${ }^{2}$ Department of Pharmacology, Faculty of Medicine, Assiut University, Egypt \\ ${ }^{3}$ Physiotherapy Department, Faculty of Applied Medical Sciences, Umm Al-Qura University, Al Abdeyah, Makkah, PO Box 7607, KSA \\ ${ }^{4}$ Pathology Department, Faculty of Medicine, Umm Al-Qura University, Al Abdeyah, Makkah, KSA
}

\begin{abstract}
Background: Wet cupping (Hejamah) has been used as alternative treatment for several diseases.

Objectives: To measure the effects of hejamah treatment for 2 consecutive months in healthy young adult men on blood pressure, blood glucose, lipid profile, serum sodium and potassium.

Materials and methods: 16 participants were treated with hejamah for 2 consecutive months. Blood pressure was measure before and 30 minutes after the treatment. Blood samples were collected from all participants before and 48 hours after hejamah and all participants were fasting for 12 hours before sample collection.

Results: Diastolic blood pressure, but not systolic, was significantly decreased following therapy $(P<0.05)$ Fasting blood glucose was significantly decreased before the treatment in the second month only. The levels of serum triglycerides significantly decreased after the first treatment and remained low in the 2nd month. There was no significant difference between the different time points in total cholesterol except for the 48 hours of the second month compared to the samples collected before the procedure of the same month. There was a significant decrease in LDL and significant increase in HDL following hejamah therapy $(P<0.05)$. Significant decrease in sodium and significant increase in potassium 48 hours following treatment with hejamah was observed in the 2 months $(P<0.05)$.

Conclusions: The performance of hejamah during fasting state could represent a useful complementary method for the regulation of diastolic blood pressure and prevention/treatment of risk factors associated with cardiovascular diseases. Further studies are required to explore the role of hejamah in controlling blood pressure and prevention of cardiovascular diseases.
\end{abstract}

Keywords: Wet cupping; Hejamah; Cardiovascular diseases; Blood pressure; Lipid profile; Sodium; Potassium

\section{Introduction}

Cardiovascular Diseases (CVDs) are major health problems and they are associated with mortality and morbidity. Several risk factors have been associated with the pathogenesis of CVDs, including metabolic disorders (e.g. hyperlipidaemia, diabetes mellitus, etc.) and increase salt intake that are major etiological factors for hypertension (HTN), coronary heart disease (CHD) and stroke [1-3]. The World Health Organization (WHO) has reported that CVDs are responsible for $30 \%$ of all deaths, which is equivalent to the combined death rates associated with several other medical conditions [4]. The estimated number of death due to CVDs by the WHO is 17.3 million people per year and the number is expected to increase to 23.3 million/year in $2030[4,5]$.

Several benefits for Complementary Medicine (CM)/Alternative Medicine (AM), also known as traditional medicine, have been shown and it is effective in the prevention of disease, treatment of non-communicable diseases, and improvement of the quality of life for persons living with chronic diseases [6]. The WHO has been encouraging the implementation of traditional medicine since many patients are not satisfied by the outcomes of modern medicine particularly those related to chronic diseases [7].

Several CMs and AMs have been suggested for the control/ treatment of HTN [8]. Blood-letting/leeching by phlebotomy significantly decreased the Blood Pressure (BP) compared to triple therapy in resistant hypertension [9]. Similar results were also seen in patients suffering from erythropoietin-induced malignant HTN [10] and post-transplant HTN associated with erythrocytosis [11].

Hejamah is a traditional Islamic treatment and a part of the prophetic medicine recommended by the prophet Mohammed, Peace Be Upon Him (PBUH), and it is used for the treatment of a variety of medical conditions [12]. Hejamah is a form of cupping therapy, also known as wet-cupping, blood leach or blood-letting therapy [12-16]. According to the prophetic medicine, hejamah should be performed at specific times during the odd days of full moon (day 17, 19 and 21) in the lunar months (Islamic calendar) and the patients should be fasting [17].

Cupping has been recommended by several physicians for CVDs [18-20]. A recent meta-analysis has reported that using cupping therapy is beneficial in controlling and lowering BP [21]. Similar

*Corresponding author: Bassem Refaat, Laboratory Medicine Department, Faculty of Applied Medical Sciences, Umm Al-Qura University, Makkah, PO Box 7607, KSA, Tel: +966 541162707; Fax: +966 125270000 Ext: 4242; E-mail: Bassem.refaat@yahoo.co.uk

Received Janaury 03, 2013; Accepted Janaury 17, 2014; Published Janaury 20 2014

Citation: Refaat B, El-Shemi AG, Ebid AA, Ashshi A, BaSalamah MA (2014) Islamic Wet Cupping and Risk Factors of Cardiovascular Diseases: Effects on Blood Pressure, Metabolic Profile and Serum Electrolytes in Healthy Young Adult Men. Altern Integ Med 3: 151. doi:10.4172/2327-5162.1000151

Copyright: (C) 2014 Refaat B, et al. This is an open-access article distributed under the terms of the Creative Commons Attribution License, which permits unrestricted use, distribution, and reproduction in any medium, provided the original author and source are credited. 
Citation: Refaat B, El-Shemi AG, Ebid AA, Ashshi A, BaSalamah MA (2014) Islamic Wet Cupping and Risk Factors of Cardiovascular Diseases: Effects on Blood Pressure, Metabolic Profile and Serum Electrolytes in Healthy Young Adult Men. Altern Integ Med 3: 151. doi:10.4172/23275162.1000151

Page 2 of 7

results were also reported on mean arterial pressure [22]. However, a recent study by Zarei et al. [23] failed to show beneficial effects on anthropometric and BP compared to diet treatment in patients with HTN [23]. Additionally, acupuncture combined with cupping therapy could improve clinical symptoms, enhance tolerance of exercise, and reduce angina frequency, duration and consumption of nitrates of the patients with stable exertional angina with fewer side effects [20,24]. Furthermore, cupping has been used in stroke rehabilitation with potential benefits. However, evidence for the effectiveness of cupping in this area is not strong due to the lack of randomized controlled trials $[21,25,26]$.

Increase in blood cholesterol level is a major risk factor for HTN and CVDs. Blood donation has been shown to significantly reduce the levels of serum cholesterol and thus decreasing the risk for CVDs among blood donors [27-30]. Blood donation significantly decreased Low Density Lipoprotein (LDL) compared to the patients treated with gemfibrozil only [27]. Phlebotomy has been recommended to reduce serum lipoprotein levels [28,30]. Wet cupping has also been shown to decrease the levels of total cholesterol and LDL and increases the level of High Density Lipoprotein (HDL) [31,32]. Additionally, bloodletting has been shown to increase the insulin sensitivity, which is a major risk factor for metabolic syndrome [33].

Our study objectives were to measure the effect of performing Islamic hejamah for two consecutive months in healthy young adult men on their blood pressure, serum sodium and potassium, serum cholesterol, triglycerides, LDL and HDL and blood glucose levels.

\section{Materials and Methods}

\section{Ethical approval}

The study was approved by the institutional review board and ethics committee of Faculty of Applied Medical Sciences (AMSEC10-15-03-2013). All samples were collected following obtaining informed written consent from all the participants.

\section{Study design}

This was a prospective analytical study. Sixteen healthy young adult men aged between 18 and 25 years were recruited into the study according to the inclusion and exclusion criteria (Table 1). Wet cupping was performed on the study subjects for 2 consecutive months according to the Islamic protocol. All participants were asked to be fasting for at least 12 hours and blood pressure and a blood sample were obtained before the initiation of the procedure. At the end of the session, another measurement of blood pressure was obtained 30 minutes after the termination of wet cupping. A second blood sample was obtained from the participants 48 hours later and they were all fasting for 12 hours. The same procedures were followed in the second month of the study.

\begin{tabular}{|l|l|}
\hline Principal inclusion criteria & Principle exclusion criteria \\
\hline Patient age $\geq 18$ and $<30$ years. & Patient age $<18$ years or $\geq 30$. \\
\hline $\begin{array}{l}\text { No chronic disease (e.g. HTN, diabetes } \\
\text { mellitus, renal failure, etc.) }\end{array}$ & $\begin{array}{l}\text { Chronic disease (Renal failure, coronary } \\
\text { heart disease, etc.) }\end{array}$ \\
\hline $\begin{array}{l}\text { Not using any drug on regular basis } \\
\text { during the previous } 3 \text { months prior to the } \\
\text { study (e.g. antibiotics, analgesics, etc.) }\end{array}$ & Using medical drugs on regular basis \\
\hline $\begin{array}{l}\text { Willing to comply with the required } \\
\text { fasting state and the full duration of the } \\
\text { study }\end{array}$ & $\begin{array}{l}\text { Not willing to comply with the study } \\
\text { protol }\end{array}$ \\
\hline
\end{tabular}

Table 1: Principles inclusion and exclusion criteria.

\section{Types of samples}

Five $\mathrm{ml}$ of blood was collected before the initiation and 48 following the termination of wet cup therapy in each month. A total of 64 samples were collected and the serum was separated by centrifugation for 15 minutes at $15000 \mathrm{RPM}$ and it was stored in $-20^{\circ} \mathrm{C}$ freezer till processed.

\section{Wet cupping protocol}

The 16 participants were divided into 3 groups as follow: Group 1 included 6 participants and they were requested to attend fasting for cup therapy on the morning of the $17^{\text {th }}$ of lunar month (Islamic calendar). The second and third groups included 5 participants each and they were requested to attend on the $19^{\text {th }}$ and $21^{\text {st }}$ day of the lunar month, respectively. Before the initiation of cup therapy, the participants were given instructions on the procedure and the planned steps of the protocol. Blood pressure was measured and $5 \mathrm{ml}$ of venous blood was obtained before the commencement of the procedures.

Cupping therapy were performed using six points on the back of each participants and they were as follow: a) two cups for the lower end of the neck cervical vertebrate (C7) and thoracic vertebrate (T2), b) two cups on each scapula and c) two cups lateral to the lumbar vertebrate (L3). The sites of cupping were identified on the back of the participants and they were sterilized using alcohol swabs. The wetcupping procedures lasted 15 minutes per participant and the steps were as follow:

Primary sucking: The cups were placed on the designated sites and a negative pressure was created by manual suction using the provided pump with the kit. The cups were left for a period of 5 minutes after ensuring their firm attachment to the skin.

Incision: The cups were removed and 10-12 superficial incisions were made on each designated area of the skin using sterile surgical blades.

Blood-letting: After soaking the cups, they were replaced back on the designated areas of the skin and negative pressure was created as previously described. The cups were left on the skin till they were filled with blood from the capillary vessels.

Removal: The cups were removed approximately after 3 minutes and new cups were placed on the same areas as previously mentioned. The used cups were socked in betadine for sterilization.

Blood-letting: The process of blood-letting was repeated for 3 times in total.

Clean and sterilise: The cupping areas were cleaned using betadine followed by placement of clean dressing.

Following the termination of cupping therapy, each participant was offered $125 \mathrm{ml}$ of fruit juice and blood pressure was recorded 30 minutes later. Same procedures were followed for the other 2 groups and during the 2 months duration of the study. Another $5 \mathrm{ml}$ blood samples were collected from each participant 48 hours following the termination of cupping therapy and all the participants were also fasting for 12 hours.

\section{Measurement of blood pressure, metabolic parameters and serum electrolytes}

Blood pressure was measured using conventional sphygmomanometer and a stethoscope (Welch Allyn Inc, NY, USA). All serum samples were processed using Cobas 6000 analyzer (Roche Diagnostics, IN, USA) to measure blood levels of glucose, triglycerides, 
Citation: Refaat B, El-Shemi AG, Ebid AA, Ashshi A, BaSalamah MA (2014) Islamic Wet Cupping and Risk Factors of Cardiovascular Diseases: Effects on Blood Pressure, Metabolic Profile and Serum Electrolytes in Healthy Young Adult Men. Altern Integ Med 3: 151. doi:10.4172/23275162.1000151

Page 3 of 7

total cholesterol, HDL, LDL, sodium and potassium.

\section{Statistical analysis}

Statistical analysis of the results was performed using SPSS version 16 . Normality and homogeneity of data were assessed with the Kolmogorov and Smirnoff test and Levene test, respectively. Pairedsamples $\mathrm{T}$ test was used to compare between the different time points of the study (before and after the intervention). $\mathrm{P}$ value $<0.05$ was considered significant.

\section{Results}

\section{Effects of hejamah on Metabolic Profile}

Overall, the results showed significant alterations in the levels of fasting blood glucose, total cholesterol, triglycerides, HDL and LDL following 2 months of wet cup therapy compared to the results obtained before the initiation of the procedure.

Fasting blood sugar: Although a slight increase in Fasting Blood
Sugar (FBS) was detected 48 hours after therapy in the first month, there was no significant difference between samples collected before and 48 hours later during the first month $(\mathrm{P}>0.05)$. However, a significant decrease was detected in samples collected before the initiation of the procedure in the $2^{\text {nd }}$ month compared to the two collected samples during the first month ( $\mathrm{p}=0.002$ and 0.0005 , respectively). Still, a significant increase in FBS level was observed in the $2^{\text {nd }}$ month in samples collected 48 hours following therapy $(\mathrm{p}=0.001)$ compared to those obtained before the initiation of the treatment in the same month. There was no significant difference between samples of 48 hours $\left(2^{\text {nd }}\right.$ months) and the two samples collected at the first month (Figure 1).

Lipid profile: Serum triglycerides decreased significantly 48 hours after the commencement of the therapy during the first month $(p=0.003)$ and it remained significantly lower in the two collected samples in the second month compared to the 2 samples of the first month. However, there was no difference between the 48 hours of the first month, before and 48 hours of the second month (Figure 1).

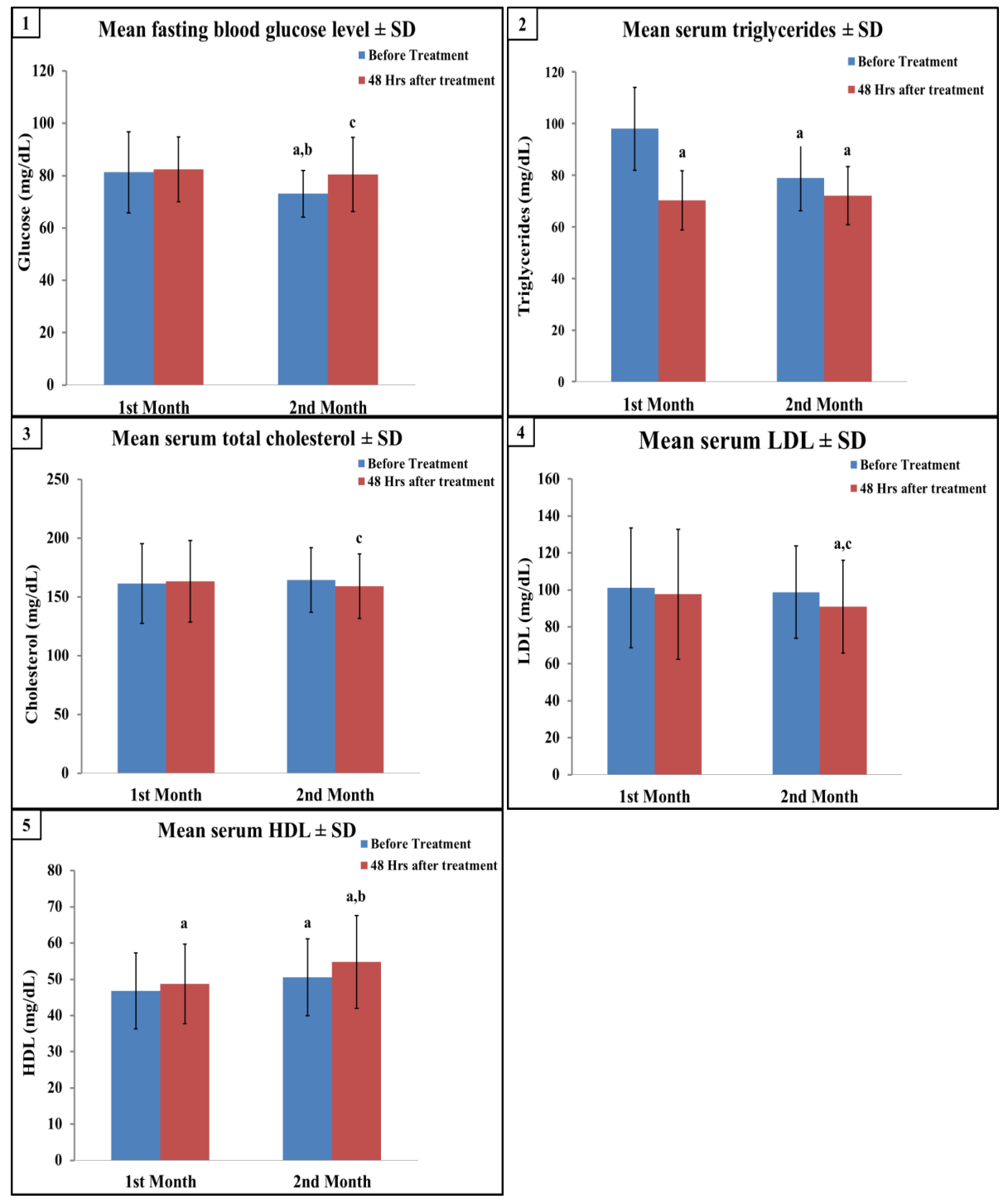

Figure 1: Mean \pm SD of (1) fasting blood glucose, (2) triglycerides (3) total cholesterol (4) LDL and (5) HDL in the different times of the study. (a=p<0.05 compared to before $1^{\text {st }}$ month, $b=p<0.05$ compared to 48 hours of $1^{\text {st }}$ month and $c=p<0.05$ compared to before of the $2^{\text {nd }}$ month). 
Citation: Refaat B, El-Shemi AG, Ebid AA, Ashshi A, BaSalamah MA (2014) Islamic Wet Cupping and Risk Factors of Cardiovascular Diseases: Effects on Blood Pressure, Metabolic Profile and Serum Electrolytes in Healthy Young Adult Men. Altern Integ Med 3: 151. doi:10.4172/23275162.1000151

Page 4 of 7

There was no significant difference between the different time points in total cholesterol except for the 48 hours of the second month compared to the samples collected before the procedure of the same month (Figure 1). LDL significantly decreased in samples collected 48 hours after the procedure in the second month compared to the initial sample (before) of the $1^{\text {st }}$ and $2^{\text {nd }}$ month of therapy. However, there was no significant difference between the two 48 hours samples collected in the $1^{\text {st }}$ and $2^{\text {nd }}$ month (Figure 1 ). HDL was significantly elevated 48 hours after the commencement of the treatment during the $1^{\text {st }}$ month and it reached its peak at the end of the study in the 48 hours samples of $2^{\text {nd }}$ month, which was significantly higher compared to the other time points of the study (Figure 1).

\section{Effect of cup therapy on blood pressure}

There was no significant change in systolic blood pressure during the different times of the study $(\mathrm{p}>0.05)$. However, a significant decrease in diastolic pressure was detected 48 hours after treatment during the first month compared to before treatment ( $p=0.002)$, and

\begin{tabular}{|l|l|l|l|l|}
\hline & \multicolumn{2}{|c|}{$1^{\text {st }}$ Month } & \multicolumn{2}{c|}{$2^{\text {nd }}$ Month } \\
\hline & Before & $\begin{array}{l}\mathbf{3 0} \text { minutes } \\
\text { after }\end{array}$ & Before & $\begin{array}{l}\mathbf{3 0} \text { minutes } \\
\text { after }\end{array}$ \\
\hline $\begin{array}{l}\text { Systolic pressure } \\
\text { (mmHg) }\end{array}$ & $115.3 \pm 10.08$ & $113.6 \pm 7.1$ & $116.9 \pm 7.3$ & $117.5 \pm 4.8$ \\
\hline $\begin{array}{l}\text { Diastolic pressure } \\
(\mathrm{mmHg})\end{array}$ & $77.3 \pm 5.31$ & $69.7 \pm 10.8^{\mathrm{a}}$ & $76.18 \pm 5.4$ & $71.2 \pm 6.7^{\mathrm{a}, \mathrm{c}}$ \\
\hline
\end{tabular}

Table 2: Mean \pm SD of systolic and diastolic pressures during the different time points of the study $\left(a=p<0.05\right.$ compared to before of $1^{\text {st }}$ month, $c=p<0.05$ compared to before of the $2^{\text {nd }}$ month)

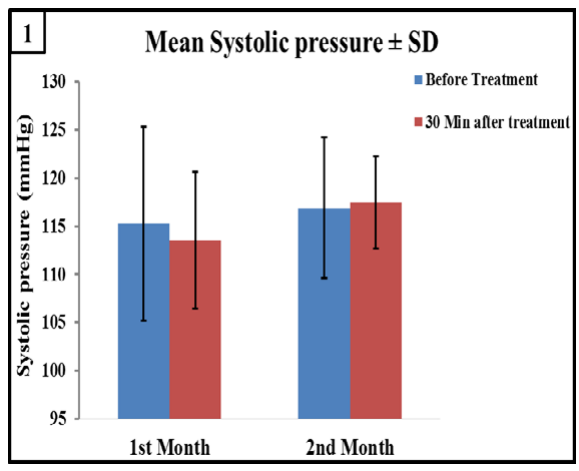

between 48 hours after treatment in the $2^{\text {nd }}$ month compared to before treatment of $1^{\text {st }}$ month $(\mathrm{p}=0.006)$ and before treatment of the $2^{\text {nd }}$ month $(\mathrm{p}=0.0003)$ (Table 2 and Figure 2$)$.

\section{Effect of cup therapy of blood sodium and potassium}

Sodium levels varied during the study. Sodium decreased significantly 48 hours after therapy during the first month compared to the collected sample before treatment $(\mathrm{p}<0.001)$. However, a significant increase was detected before the initiation of therapy in the $2^{\text {nd }}$ month compared to the 48 hours of the first month $(\mathrm{p}=0.004)$. Interestingly, the levels of sodium decreased once more 48 hours after treatment in the $2^{\text {nd }}$ month compared to the 3 previous time points (Table 3 ) (Figure 3 ).

Potassium levels were opposite to sodium, where a significant increase was observed 48 hours following treatment in the $1^{\text {st }}$ month ( $p=0.0002$ ). This was followed by a significant decrease in the sample collected before the initiation of therapy in the second month compared to the previous time point $(\mathrm{p}=0.04)$. The second cup therapy resulted in a significant increase in potassium levels 48 hours following the treatment compared to 3 previous time points (Table 3 and Figure 3).

\section{Discussion}

Both bleeding and cupping belong to the oldest medical procedures practiced in the human history and the therapeutic potential of cupping therapy is unlimited and the secrets of its mechanisms still mysterious. Wet cupping/hejamah are part of the traditional medicine in the Arab and Islamic world as the Prophet Mohammad (peace be upon him) said: "If there is a benefit in any of your treatment modalities, benefit

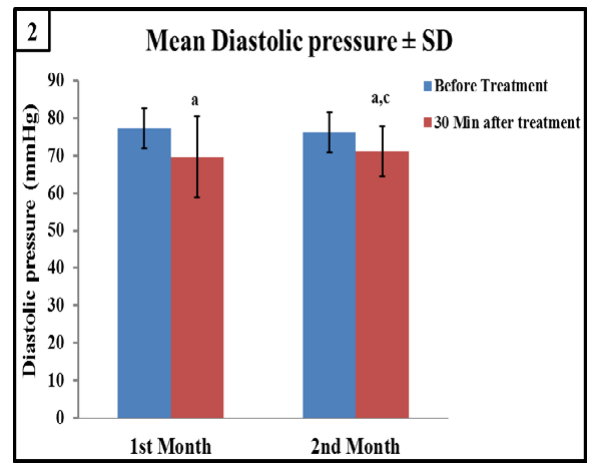

Figure 2: Mean $\pm S D$ of (1) systolic and (2) diastolic blood pressure in the different times of the study. (a=p<0.05 compared to before $1^{\text {st }}$ month, $b=p<0.05$ compared to 30 minutes of $1^{\text {st }}$ month and $c=p<0.05$ compared to before of the $2^{\text {nd }}$ month).
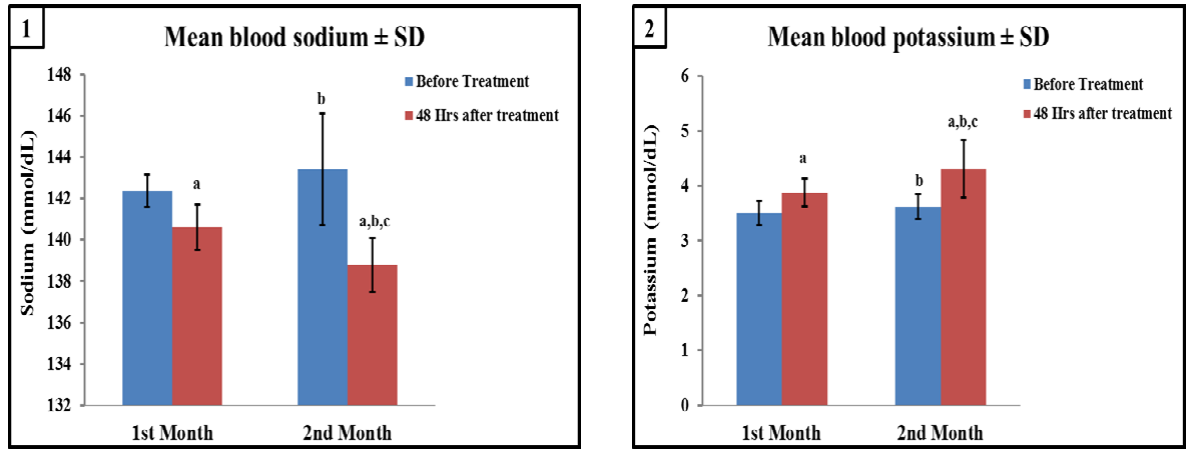

Figure 3: Mean \pm SD of blood levels of (1) sodium and (2) potassium in the different times of the study. (a=p $<0.05$ compared to before 1 st month, $b=p<0.05$ compared to 48 hours of $1^{\text {st }}$ month and $c=p<0.05$ compared to before of the $2^{\text {nd }}$ month). 
Citation: Refaat B, El-Shemi AG, Ebid AA, Ashshi A, BaSalamah MA (2014) Islamic Wet Cupping and Risk Factors of Cardiovascular Diseases: Effects on Blood Pressure, Metabolic Profile and Serum Electrolytes in Healthy Young Adult Men. Altern Integ Med 3: 151. doi:10.4172/23275162.1000151

Page 5 of 7

\begin{tabular}{|l|l|l|l|l|}
\hline & \multicolumn{3}{|l|}{$1^{\text {st }}$ Month } & $2^{\text {nd }}$ Month \\
\hline & Before & $\mathbf{4 8}$ hours after & Before & 48 hours after \\
\hline Fasting Blood Sugar (mg/dL) & $81.36 \pm 15.5$ & $82.5 \pm 12.4$ & $73.1 \pm 8.9^{\mathrm{a}, \mathrm{b}}$ & $80.5 \pm 14.2 \mathrm{c}$ \\
\hline Triglycerides $(\mathrm{mg} / \mathrm{dL})$ & $98 \pm 16.1$ & $70.3 \pm 11.4^{\mathrm{a}}$ & $78.9 \pm 12.6^{\mathrm{a}}$ & $72.05 \pm 11.3^{\mathrm{a}}$ \\
\hline Total Cholesterol $(\mathrm{mg} / \mathrm{dL})$ & $161.4 \pm 33.9$ & $163.09 \pm 34.7$ & $164.4 \pm 27.5$ & $159.1 \pm 23.4^{\mathrm{c}}$ \\
\hline LDL $(\mathrm{mg} / \mathrm{dL})$ & $101.04 \pm 32.4$ & $97.6 \pm 35.2$ & $98.8 \pm 25.07$ & $91 \pm 25.1^{\mathrm{a}, \mathrm{c}}$ \\
\hline HDL $(\mathrm{mg} / \mathrm{dL})$ & $46.76 \pm 10.5$ & $48.7 \pm 11^{\mathrm{a}}$ & $50.51 \pm 10.6^{\mathrm{a}}$ & $54.8 \pm 12.8^{\mathrm{a}, \mathrm{c}}$ \\
\hline Sodium $(\mathrm{mmol} / \mathrm{dL})$ & $142.37 \pm 0.8$ & $140.6 \pm 1.1^{\mathrm{a}}$ & $143.4 \pm 2.7^{\mathrm{b}}$ & $138.8 \pm 1.3^{\mathrm{a}, \mathrm{b}, \mathrm{c}}$ \\
\hline Potassium $(\mathrm{mmol} / \mathrm{dL})$ & $3.6 \pm 0.22$ & $3.88 \pm 0.25^{\mathrm{a}}$ & $3.62 \pm 0.23$ & $4.31 \pm 0.52^{\mathrm{a}, \mathrm{b}, \mathrm{c}}$ \\
\hline
\end{tabular}

Table 3: Mean \pm SD of fasting blood sugar, blood triglycerides, total cholesterol, $\mathrm{LD}, \mathrm{HDL}$, sodium and potassium levels during the different time points of the study ( $a=p<0.05$ compared to before of $1^{\text {st }}$ month, $b=p<0.05$ compared to 48 hours of $1^{\text {st }}$ month and $c=p<0.05$ compared to before of the $2^{\text {nd }}$ month).

will be in the blade puncture in cupping therapy" $[12,17,18,34]$.

The current study aimed to evaluate the effects of cupping therapy on BP, lipid profile and sodium/potassium blood levels, as well as on FBS. Our results showed significant decrease in end of the study period in diastolic BP accompanied by a significant decrease in serum sodium and significant increase in serum potassium. Additionally, there was a significant increase in HDL, and a significant decrease in LDL and triglycerides. Finally, FBS was variable and inconsistent during the study.

There are several drawbacks to our study. First, the sample size is small and the study included only healthy subjects. However, several other reports were conducted on similar participant number and our results showed significant difference before and after the treatment [9-11]. Another limitation is that we did not measure hormones (e.g. aldosterone, cortisol, etc.) that are known to play an important role in the regulation of metabolic parameters, sodium, potassium and BP. However, this is a preliminary report and a large randomised control trial has been planned.

Elevated BP and hypertension are major risk factors for CVDs, especially CHD, stroke and heart failure, as well as renal failure [35,36]. It has been estimated that high BP is involved in $49 \%$ of all chronic heart diseases and $62 \%$ of all stroke incidences [37-39]. Nearly 50\% of adults worldwide are estimated to be hypertensive or experiencing episodes of raised BP [35,36]. More importantly, all currently used antihypertensive drugs, without exception, have several dosedependent side effects [35,36].

$\mathrm{CM}$ has been suggested for the control/treatment of hypertension [8]. A recent meta-analysis that included tow randomized controlled trials using wet and dry cupping in the treatment of hypertension has reported that using cupping therapy is beneficial in controlling and lowering BP [21]. Similar results were also reported by another study on 15 healthy men and the authors have shown a significant decrease in the mean arterial pressure following wet cupping therapy [22]. In the present study, application of cupping therapy resulted in a significant decrease in the diastolic BP at 30 minutes after cupping. Therefore, hejamah is a potential therapy that could be used as prophylactic and/ or complementary treatment for the prevention and control of HTN.

Sodium is essential nutrient that is involved in several homeostatic processes $[38,40]$. There is a compelling body of evidence that that hypernatremia or a high salt intake strongly contribute to the development of HTN and CVDs, whereas reduced sodium consumption decreases BP [41-43]. Also, potassium is an essential nutrient that is needed for maintenance of total body fluid volume, acid and electrolyte balance, and normal cell function [37]. Previous systematic reviews have suggested that increased potassium intake lowers blood pressure in adults with and without hypertension [37]. A recent 11 cohort studies reported an inverse association between blood potassium level and risk of hypertension and stroke [44]. Also, in a more recent systemic review that included 22 randomised controlled trials in adults confirm that increased potassium intake reduces systolic and diastolic BP as well as improve the prevention and control of the stroke [37].

Our results correlate with the previous studies as they showed a significant decrease in diastolic BP accompanied by a significant decrease in serum sodium and significant increase in serum potassium at the end of the study. Taken together, our findings suggest that hejamah decreases the BP by modulating the blood concentrations of sodium and potassium. However, despite that the observed significant alteration in serum electrolytes in the present study were within the normal range, measuring the concentrations of adrenal cortex hormones, blood and urine $\mathrm{pH}$ would exclude pathological causes of hyponatremia such as hypoadrenalism and/or type 4 renal tubular acidosis. Therefore, further research are necessary to reveal the mechanism(s) by which hejamah regulate BP and serum electrolytes.

Increase in blood cholesterol levels is a major risk factor for CVDs. Blood donation and phlebotomy have been shown to significantly reduce the levels of serum cholesterol and thus decreasing the risk for CVDs [30]. Rukzan et al. [45] conducted a study to evaluate the effect of cupping therapy on serum lipid profile concentration in 31 men (35 to to 55 years old), with hyperlipidaemia and who were not using diet or drug therapy. The serum levels for total cholesterol, LDL, triglyceride, and HDL were determined before cupping and then once a week for two weeks after cupping. Cupping significantly decreased total cholesterol, LDL, and LDL/HDL ratio compared to before cupping [45]. Moreover, similar results have been reported by other studies $[31,32]$.

The results of the current study are in agreement with the previous observations. There was a significant decrease observed in triglycerides after the first treatment and the levels remained significantly low till the end of the study. Additionally, there was a significant decrease in LDL and significant increase in HDL observed in samples collected 48 hours of the second treatment. However, there was no significant change in the levels of total cholesterol. Further studies are required to illustrate the role of hejamah in the regulation of the lipid profile.

Bloodletting has been shown to increase the insulin sensitivity [33], which is a major risk factor for the development of metabolic syndrome if impaired. In a constant line, Ranaei-siadat and his colleagues measured the venous blood concentrations of several molecules before and after five times of cupping (one time per month) in young healthy males (20-27 years). Interestingly, their results showed that cupping can regulate cholesterol, HDL, LDL and FBS. However, in the present study the effect of cupping on fasting glucose level was variable and not constant. This could be due to the difference in study design or the small sample size between our study and the previous reports. Additionally, the observed increase in FBS 48 hours following treatment could be due to an increase in the production of glucocorticoids, which are known to be released during stress and they are potent inducers of hyperglycaemia [46].

Though cupping therapy has been used for thousands of years as a traditional therapy for various ailments, the underlying mechanism that mediates its beneficial effect is still obscure. Many questions arise from time to time about the exact role of cupping in treating diseases and to explain benefits of cupping therapy. It was suggested that cups produce hyperaemia or haemostasis which results in a therapeutic effect [13]. Michalsen et al. [47] postulated that cupping gathers and removes 
Citation: Refaat B, El-Shemi AG, Ebid AA, Ashshi A, BaSalamah MA (2014) Islamic Wet Cupping and Risk Factors of Cardiovascular Diseases: Effects on Blood Pressure, Metabolic Profile and Serum Electrolytes in Healthy Young Adult Men. Altern Integ Med 3: 151. doi:10.4172/23275162.1000151

Page 6 of 7

harmful blood [47], which also has been discussed and suggested in the 'Taibah Theory' by El-Sayed et al. [12] and, by the findings of Bilal et al. [48] and Ranaei-siadat et al. [46]. Rukzan et al. [45] demonstrated that cupping therapy enhances blood circulation, treats congestion, stops the inflammatory extravasations from the tissues, affect the autonomic nervous system, and reduces pain [45]. It was also reported that injury to the skin leads to the release of $\beta$-endorphin and adrenocortical hormones into the systemic circulation [49].

Therefore, the observed significant variations in BP, lipid profile and serum electrolytes could be due to the removal of harmful substances and the induction of several other molecules that are involved in the modulation of lipid metabolism and body water content. However, future research is mandatory to explore the mechanism(s) by which hejamah regulates the blood pressure.

In conclusion, hejamah/wet cupping could represent a potential beneficial line of therapy used as a prophylactic and/or complementary for lowering blood pressure by modulating serum sodium and potassium. It also could provide protection against CVDs by decreasing LDL and increasing HDL. However, large randomised control trials using Islamic protocol of wet cupping in patients with HTN and hyperlipidaemia are required. Furthermore, measuring the effect of Islamic wet cupping on the serum levels of aldosterone, cortisol, adrenaline and thyroid hormones could provide a better understanding on the underlying mechanism(s) by which it could affect the metabolic parameters.

\section{References}

1. Labarthe DR (2012) From cardiovascular disease to cardiovascular health: a quiet revolution? Circ Cardiovasc Qual Outcomes 5: e86-92.

2. Whelton PK, Appel LJ, Sacco RL, Anderson CA, Antman EM, et al. (2012) Sodium, blood pressure, and cardiovascular disease: further evidence supporting the American Heart Association sodium reduction recommendations. Circulation 126: 2880-2889.

3. Labarthe DR, Dunbar SB (2012) Global cardiovascular health promotion and disease prevention: 2011 and beyond. Circulation 125: 2667-2676.

4. Rehm J, Mathers C, Popova S, Thavorncharoensap M, Teerawattananon Y, et al. (2009) Global burden of disease and injury and economic cost attributable to alcohol use and alcohol-use disorders. Lancet 373: 2223-2233.

5. Ng N, Johnson O, Lindahl B, Norberg M (2012) A reversal of decreasing trends in population cholesterol levels in Västerbotten County, Sweden. Glob Health Action 5

6. Burge SK, Albright TL (2002) Use of complementary and alternative medicine among family practice patients in south Texas. Am J Public Health 92: 16141616.

7. WHO (2002) WHO Traditional Medicine Strategy 2002-2005: World Health Organization, Geneva, Switzerland.

8. Nahas R (2008) Complementary and alternative medicine approaches to blood pressure reduction: An evidence-based review. Can Fam Physician 54:15291533.

9. Zidek W, Tenschert W, Karoff C, Vetter H (1985) Treatment of resistant hypertension by phlebotomy. Klin Wochenschr 63: 762-764.

10. Fahal IH, Yaqoob M, Ahmad R (1992) Phlebotomy for erythropoietin-induced malignant hypertension. Nephron 61: 214-216.

11. Barenbrock M, Spieker C, Rahn KH, Zidek W (1993) Therapeutic efficiency of phlebotomy in posttransplant hypertension associated with erythrocytosis. Clin Nephrol 40: 241-243.

12. El Sayed SM, Mahmoud HS, Nabo MMH (2013) Methods of Wet Cupping Therapy (Al-Hijamah): In Light of Modern Medicine and Prophetic Medicine. Altern Integ Med 2:1-16.

13. Cao H, Li X, Liu J (2012) An updated review of the efficacy of cupping therapy. PLoS One 7: e31793.
14. Cao H, Hu H, Colagiuri B, Liu J (2011) Medicinal cupping therapy in 30 patients with fibromyalgia: a case series observation. Forsch Komplement Med 18:122 126.

15. Cao H, Zhu C, Liu J (2010) Wet cupping therapy for treatment of herpes zoster: a systematic review of randomized controlled trials. Altern Ther Health Med 16: $48-54$.

16. Cao H, Han M, Li X, Dong S, Shang Y, et al. (2010) Clinical research evidence of cupping therapy in China: a systematic literature review. BMC Complement Altern Med 10: 70

17. Mahmoud HS, Abou-El-Naga M, Omar NAA, El-Ghazzawy HA, Fathy YM, et al. (2013) Anatomical Sites for Practicing Wet Cupping Therapy (Al- Hijamah): In Light of Modern Medicine and Prophetic Medicine. Altern Integ Med 2: 1374 1378.

18. Hajar Albinali HA (2004) Chairman's Reflections: Blood-letting. Heart Views 5: 74-85.

19. Shaikh BT, Hatcher J (2005) Complementary and Alternative Medicine in Pakistan: Prospects and Limitations. Evid Based Complement Alternat Med 2: $139-142$.

20. Shekarforoush S, Foadoddini M (2012) Cardiac effects of cupping: myocardial infarction, arrhythmias, heart rate and mean arterial blood pressure in the rat heart. Chin J Physiol 55: 253-258.

21. Lee MS, Choi TY, Shin BC, Kim JI, Nam SS (2010) Cupping for hypertension: a systematic review. Clin Exp Hypertens 32:423-425.

22. AL-Shamma YMH, Abdil Razzaq A (2009) Al-Hijamah Cupping Therapy. Kufa Med Journal 12: 49-56.

23. Zarei M, Hejazi S, Javadi SA, and Farahani H (2012) The efficacy of we cupping in the treatment of hypertension. ARYA Atherosclerosis Journal 8: 1-4.

24. Yin LH, Miao BH, Chen J, Chai TQ (2009) Clinical study about acupuncture combined with cupping therapy for treating stable exertional angina pectoris in the middle-age or old patients. Chinese J Clin Healthcare 12: 465-467.

25. Lee MS, Choi TY, Shin BC, Han CH, Ernst E (2010) Cupping for stroke rehabilitation: a systematic review. J Neurol Sci 294: 70-73.

26. Lee MS, Kim JI, Ernst E (2011) Is cupping an effective treatment? An overview of systematic reviews. J Acupunct Meridian Stud 4: 1-4.

27. Kumar H (1994) Repeated blood donation effective in treating hyperlipidemia. J Assoc Physicians India 42: 468-469.

28. Salonen JT, Tuomainen TP, Salonen R, Lakka TA, Nyyssönen K (1998) Donation of blood is associated with reduced risk of myocardial infarction. The Kuopio Ischaemic Heart Disease Risk Factor Study. Am J Epidemiol 148: 445451.

29. Tuomainen TP, Punnonen K, Nyyssönen K, Salonen JT (1998) Association between body iron stores and the risk of acute myocardial infarction in men. Circulation 97: 1461-1466.

30. Meyers K, Falkner B (2009) Hypertension in children and adolescents: an approach to management of complex hyper-tension in pediatric patients. Curr Hypertens Rep 11: 315-322.

31. Niasari M, Kosari F, Ahmadi A (2007) The effect of wet cupping on serum lipid concentrations of clinically healthy young men: a randomized controlled trial. $J$ Altern Complement Med 13: 79-82.

32. Mustafa LA, Dawood RM, Al-Sabaawy OM (2012) Effect of Wet Cupping on Serum Lipids Profile Levels of Hyperlipidemic Patients and Correlation with some Metal lons. Raf J Sci 23: 129-136.

33. Equitani F, Fernandez-Real JM, Menichella G, Koch M, Calvani M, et al. (2008) Bloodletting ameliorates insulin sensitivity and secretion in parallel to reducing liver iron in carriers of HFE gene mutations. Diabetes Care 31: 3-8.

34. Parapia LA (2008) History of bloodletting by phlebotomy. Br J Haematol 143 490-495.

35. WHO (2012) Guideline: Sodium intake for adults and children.

36. WHO (2013) A global brief on hypertension Silent killer. Global Public Health Crisis 82.

37. Aburto NJ, Hanson S, Gutierrez H, Hooper L, Elliott P, et al. (2013) Effect of increased potassium intake on cardiovascular risk factors and disease: systematic review and meta-analyses. BMJ 346: f1378. 
Citation: Refaat B, El-Shemi AG, Ebid AA, Ashshi A, BaSalamah MA (2014) Islamic Wet Cupping and Risk Factors of Cardiovascular Diseases: Effects on Blood Pressure, Metabolic Profile and Serum Electrolytes in Healthy Young Adult Men. Altern Integ Med 3: 151. doi:10.4172/23275162.1000151

Page 7 of 7

38. Aburto NJ, Ziolkovska A, Hooper L, Elliott P, Cappuccio FP, et al. (2013) Effect of lower sodium intake on health: systematic review and meta-analyses. BMJ 346: f1326.

39. Yusuf S, Hawken S, Ounpuu S, Dans T, Avezum A, et al. (2004) Effect of potentially modifiable risk factors associated with myocardial infarction in 52 countries (the INTERHEART study): case-control study. Lancet 364: 937-952.

40. He FJ, Li J, Macgregor GA (2013) Effect of longer term modest salt reduction on blood pressure: Cochrane systematic review and meta-analysis of randomised trials. BMJ 346: f1325

41. Chobanian AV, Bakris GL, Black HR, Cushman WC, Green LA, Izzo JL, Jr, et al. (2003) Seventh report of the Joint National Committee on Prevention, Detection, Evaluation, and Treatment of High Blood Pressure. Hypertension 42: $1206-1252$

42. He FJ, Jenner KH, Macgregor GA (2010) WASH-world action on salt and health. Kidney Int 78: 745-753.

43. He FJ, MacGregor GA (2010) Reducing population salt intake worldwide: from evidence to implementation. Prog Cardiovasc Dis 52: 363-382.
44. D’Elia L, Barba G, Cappuccio FP, Strazzullo P (2011) Potassium intake, stroke and cardiovascular disease a meta-analysis of prospective studies. J Am Coll Cardiol 57: 1210-1219.

45. Rukzan LM, Al-Sabaawy DO (2012) Effect of Wet Cupping on Serum Lipids Profile Levels of Hyperlipidemic Patients and Correlation with some Metal Ions. Raf J Sci 23: 128-136.

46. Ranaei-siadat SO, Kheirandish H, Niasari, Adibi K (2004) The effect of cupping (hejamat) on blood biochemical and immunological parameters. IJPR 3: 31-32.

47. Michalsen A, Bock S, Ludtke R, Rampp T, Baecker M, et al. (2009) Effects of traditional cupping therapy in patients with carpal tunnel syndrome: a randomized controlled trial. J Pain 10: 601-608.

48. Bilal M, Khan AR, Ahmed A, Afroz S (2011) Partial Evaluation of Technique Used In Cupping. Journal of Basic And Applied Science 7: 65-68.

49. Han JS (2004) Acupuncture and endorphins. Neurosci Lett 361: 258-261. 